\title{
India's onslaught on drug patents continues
}

The Obama administration recently placed India on a 'watch list' over its lack of intellectual property protection for innovator companies. Undaunted by US concerns, India continues to pursue its own public health interests, adopting policies that support the generics industry. Thus far, most of the companies affected have been big pharma rather than biotech, although Indian authorities have revoked patents on blockbuster biologics Pegasys and Herceptin (Table 1).

Lisa Melton London

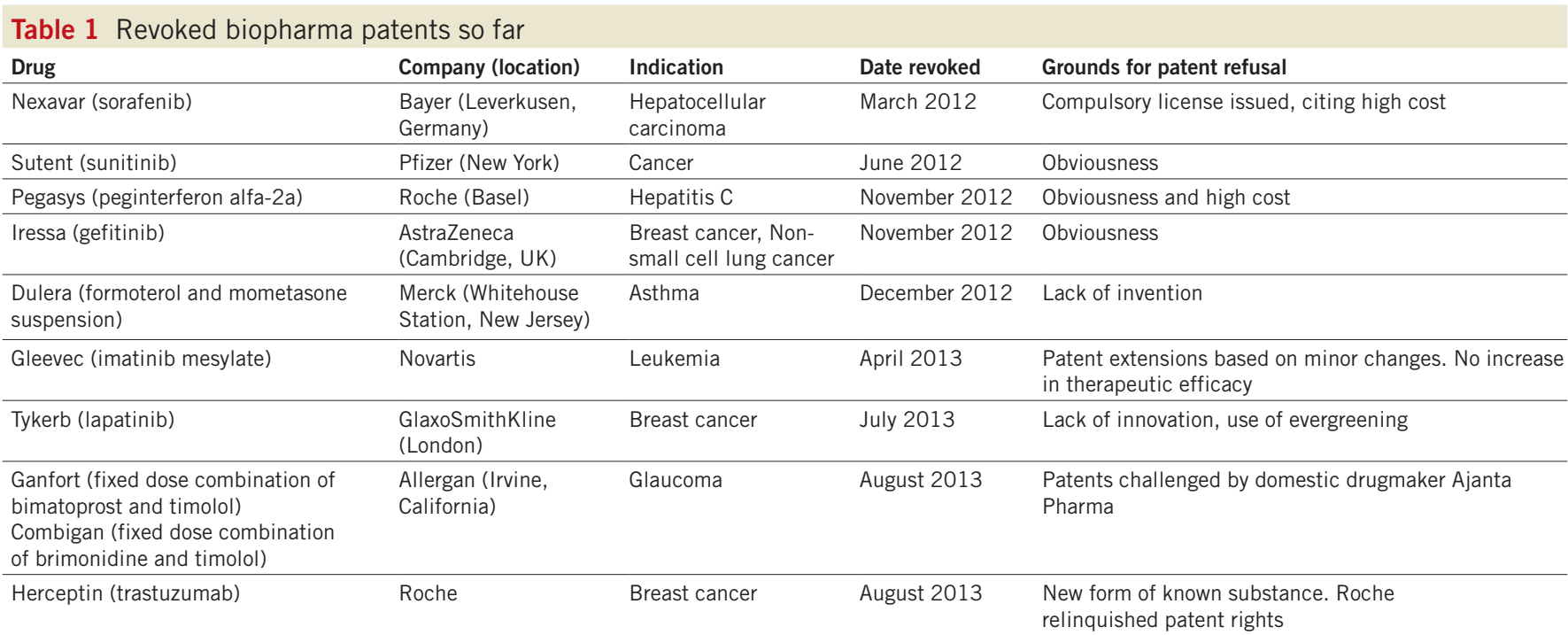

\section{Around the world in a month}

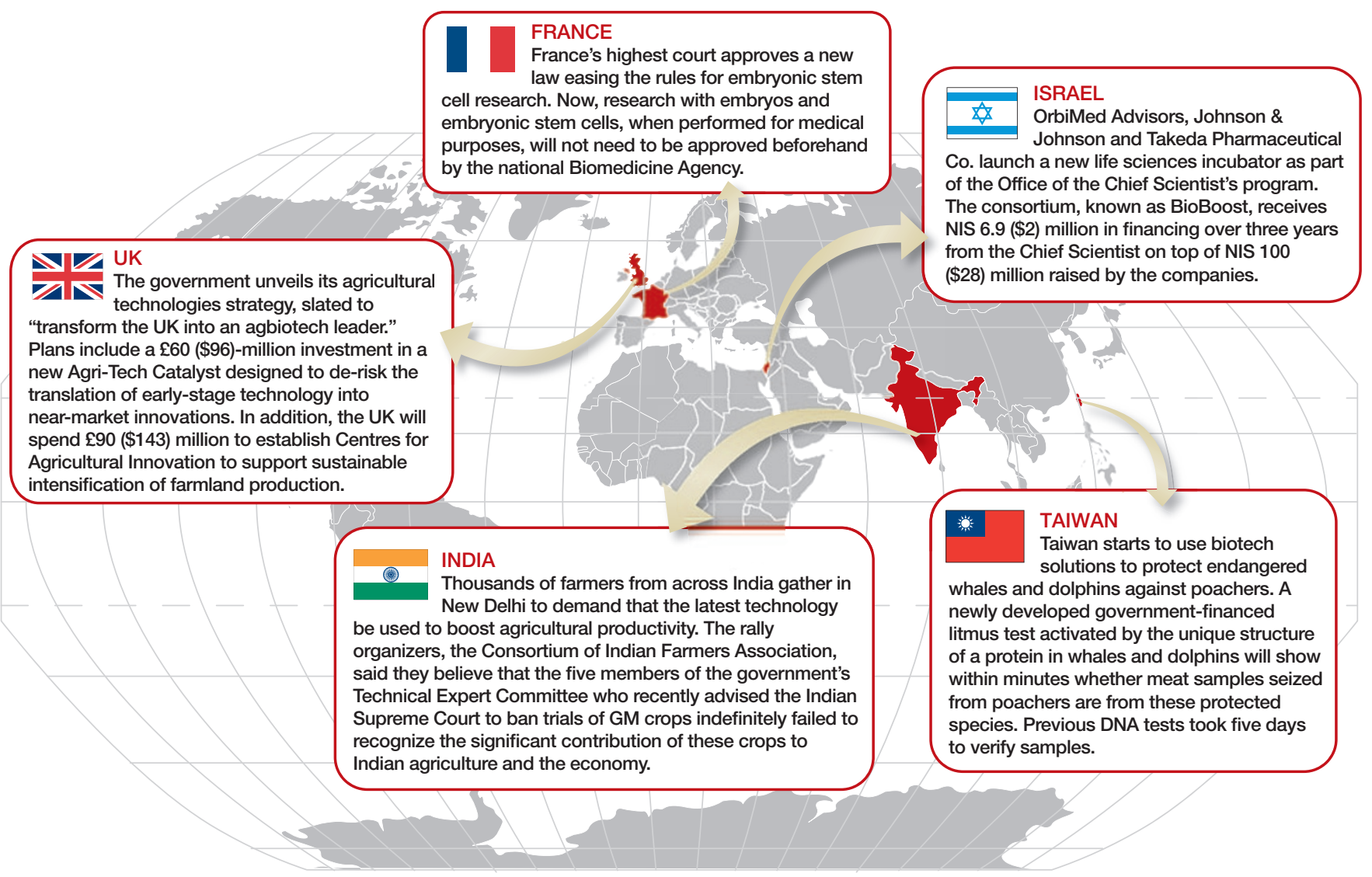

